\title{
High production indexes and key factors influencing coalbed methane (CBM) horizontal well productivity
}

\author{
Yanhui Yang, a, Shu Tao, b, Yanlei Yang, , c, Wei Tian ${ }^{1}$, Yongping Zhang ${ }^{1}$, Ning \\ Wei $^{1}$ \\ ${ }^{1}$ PetroChina Huabei Oilfield Company, Renqiu Hebei, 062552, China \\ ${ }^{2}$ School of energy resources, China University of Geosciences (Beijing), Beijing, 100083, China \\ a yjy_yyh@petrochina.com.cn, ${ }^{b}$ cugbst@126.com, ${ }^{c}$ yjzx_yyl@petrochina.com.cn,
}

Keywords: Fanzhuang block; horizontal well; geological factors; high production index

Abstract: To evaluate the development effects systematically, the coalbed methane (CBM) production performance of 58 horizontal wells in the Fanzhuang block of the Qinshui Basin was tracked and correlations between the gas rate per $100 \mathrm{~m}$ and the influencing factors were discussed by single and multiple factor analysis. The grey correlation analysis (GRA) was then applied to quantitatively evaluate the key geological factors influencing CBM horizontal well productivity. The results show that the order of geological factors influencing horizontal well productivity is burial depth, gas production capacity $(C)$, gas production potential $(P)$, ratio of critical desorption pressure to initial reservoir pressure $\left(p_{\mathrm{c}} / p_{\mathrm{i}}\right)$, gas content, and thickness, where the gas production potential and capacity can reflect the comprehensive impacts of thickness, gas content, and permeability. The larger the gas production potential or capacity is, the better the gas productivity is. The high production indexes are the depth of $300 \sim 500 \mathrm{~m}, p_{\mathrm{c}} / p_{\mathrm{i}}>0.6, \mathrm{P}>130 \mathrm{~m}^{4} / \mathrm{t}, \mathrm{C}>60 \mathrm{mD} \times \mathrm{m}^{4} / \mathrm{t}$, and far away from the faults.

\section{Introduction}

Coalbed methane (CBM) is an important source of clean energy which has been a strategic supplement to conventional natural gas ${ }^{[1]}$. As the largest consumer and producer of coal in the world, China has the third largest CBM reserves, behind those of the Russia and Canada ${ }^{[2-3]}$. With the rapid development of CBM industrialization, lower costs and higher gas production per well in CBM commercial development have gradually become important topics in CBM research.Contrast with the vertical wells, the horizontal well is one of the important drilling technologies for the development of coalbed methane, and is also the technical development trend of the development of coalbed methane, which integrates drilling, well completion and stimulation on production ${ }^{[4]}$. In view of the low permeability, strong heterogeneity of coal reservoirs in china, Huabei Oilfield introduce horizontal wells draw foreign experience of low rank coal mining during "The 11th Five" periods, and take the lead in the implementation of horizontal well development in in Fanzhuang block, southern Qinshui Basin.However, the difference of gas and water production is gradually emerging with the development of CBM horizontal wells. Compared with the vertical well, the horizontal well has a good effect of increasing production while the higest production well even up to 15 times around the vertical wells.But there are still some questions: High variation in the production of horizontal wells, and there are a lot of inefficient wells; The key factors that affect the development of horizontal wells are not clear; Low permeability and strong heterogeneity of high rank coal reservoir is difficult to optimize the high yield region of the reservoir. In order to evaluate the development effects systematically, the coalbed methane (CBM) production performance of 58 horizontal wells in the Fanzhuang block of the Qinshui Basin was tracked to point out the problems existing in the development of horizontal wells. Besides, correlations between the gas rate per $100 \mathrm{~m}$ and the influencing factors were discussed by single and multiple factor analysis. The grey correlation analysis (GRA) was then applied to quantitatively evaluate the key geological factors influencing CBM horizontal well productivity with the goal of providing theory and engineering support for the development of CBM. 


\section{The main problems in the development of multi branch horizontal wells}

(1) Coal reservoir prone to sensitivity damage: the coal seam is an organic reservoir with low permeability and easy to be polluted ${ }^{[5-6]}$. Compared with vertical wells, horizontal wells is very easy to appear reservoir sensitivity damage in the drilling process, which resulting in effective flow channel blocked and the permeability reduction. These questions lead to the production of water in unit length is below the adjacent vertical wells, and desorption pressure is difficult to reach quickly. Statistical the water production of 58 horizontal wells and the adjacent vertical wells in Fanzhuang block, we found that the water production per unit length only $0.25 \mathrm{~m}^{3}$, which is far lower than surrounding straight wells (average of $3.34 \mathrm{~m}^{3}$ ). The desorption pressure of horizontal well is also much lower than that of the vertical well, as shown in Table 1.

Table 1 Water production of horizontal well and adjacent vertical well

\begin{tabular}{ccccc}
\hline Well type & $\begin{array}{c}\mathrm{N} \\
(\text { Well })\end{array}$ & $\begin{array}{c}\text { Desorption } \\
\text { pressure } \\
(\mathrm{MPa})\end{array}$ & $\begin{array}{c}\text { Water } \\
\text { production } \\
\left(\mathrm{m}^{3}\right)\end{array}$ & $\begin{array}{c}\text { Water production } \\
\text { per unit length } \\
\left(\mathrm{m}^{3}\right)\end{array}$ \\
\hline Horizontal & 58 & 1.61 & 1089 & 0.29 \\
Vertical & 130 & 1.82 & 564 & 3.53 \\
\hline
\end{tabular}

(2) Borehole wall collapse caused by the instability of wellbore in the process of drilling: due to the attitude, coal structure, roof and high rank inherent mechanical properties of coal reservoirs, the wellbore are are easy to collapse during drilling process, which result in the diffierence between the actual horizontal trajectory and the design trajectory. These wells is is difficult to realize area reduction with low resource utilization.

(3) A large number of inefficient wells with no improvement measures: the horizontal well always use barefoot well completion, which is unable to carry out the production increase. The borehole wall will collapse in a few years after the coal seam gas exploitation, which greatly shortens the gas recovery life and reduces the efficiency of the exploration and development of CBM. It can be seen that the production of 38 horizontal wells is lower than $3000 \mathrm{~m}^{3} / \mathrm{d}$, accounted for $66 \%$ of the total number of wells (Fig.1).

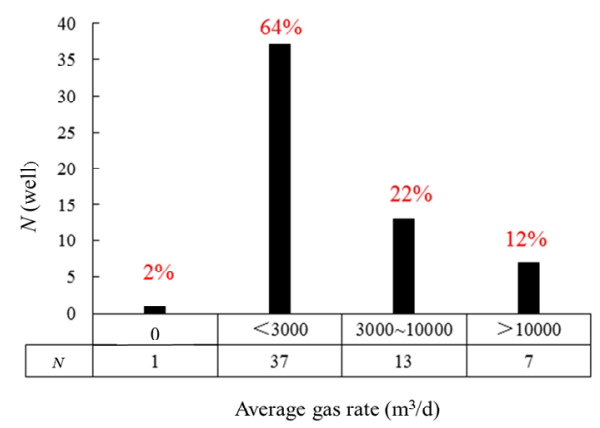

Fig. 1 Pie chart of horizontal well productivity

\section{Effects of the geological factors on the gas production}

There are some inefficient horizontal wells $\left(<3000 \mathrm{~m}^{3} / \mathrm{d}\right)$ in the Fanzhuang block, souther Qinshui basin. The geological condition is a decisive component for the high production of horizontal wells. In this study, five reservoir parameters (including the burial depth, the coal thickness, the ratio of the critical desorption pressure to the initial reservoir pressure, the gas content and the permeability) of 35 wells (away from faults with no engineering collapse) were analyzed with correlation analysis to reveal the factor that has the greatest effect on gas production of horizontal wells in the Fanzhuang block. Moreover, in order to avoid the influence of coal seam footage on gas production, the average gas rate per $100 \mathrm{~m}$ was calculated to represent the development effect of horizontal wells. 


\section{Single factors}

\section{Burial depth}

In the Fanzhuang Block, the middle depth of the target coal seams was considered the burial depth, which was used to analyze the correlation of the burial depth and gas production. Fig.2a shows that the burial depth of the target coal seam ranges from 273 to $812 \mathrm{~m}$ based on 35 data points, and there is a negative relationship between the burial depth and average gas rate per $100 \mathrm{~m}$. Overall, the average gas rate per $100 \mathrm{~m}$ decreases with the increase of the buried depth and high gas production $\left(>150 \mathrm{~m}^{3} /(\mathrm{d} / 100 \mathrm{~m})\right)$ are mainly concentrated in the depth of $250 \sim 600 \mathrm{~m}$. Besides, the burial depths more than $630 \mathrm{~m}$ is of poor gas recovery $\left(<50 \mathrm{~m}^{3} /(\mathrm{d} / 100 \mathrm{~m})\right)$. Therefore, a coal seam with a depth of from 250 to $600 \mathrm{~m}$ tends to have a much greater potential for producing CBM with horizontal wells.
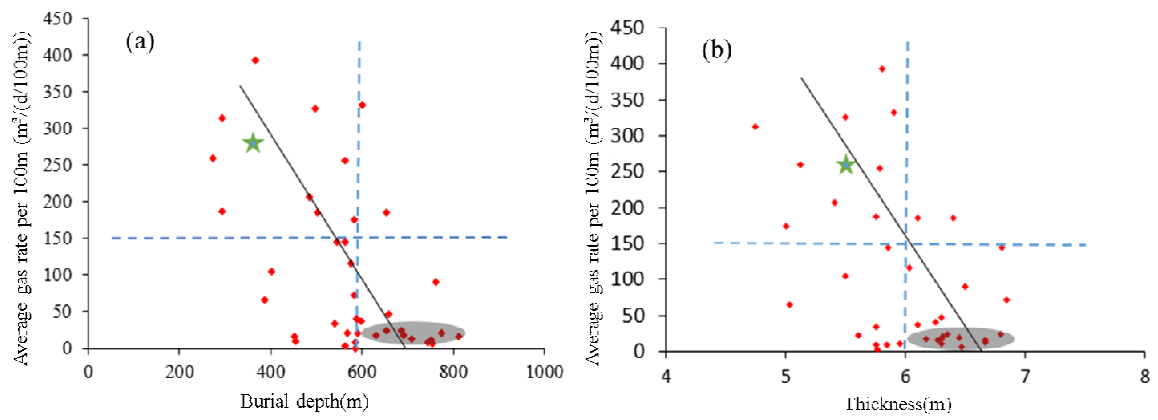

Fig. 2 Relation between average gas rate per 100m and burial depth(a), thickness(b).

\section{Thickness}

Coal seam is the fundamental for CBM accumulation ${ }^{[7]}$. Under the same conditions, the greater the thickness of the coal, the more abundant gas source with the stronger the ability of gas supply, which is favorable to the higher gas production. The thickness of coal seam can be determined according to the well logging interpretation. Fig. $2 \mathrm{~b}$ indicate that the thickness of the target coal seam ranges from 4.5 to $7 \mathrm{~m}$. However, the gas production of the horizontal well has a trend of decrease with the increase of the thickness of the coal seam, which is obviously contrary to the above understanding. This phenomenon indicates that the productivity of horizontal well is affected by many factors but not a single factor. Besides, the vertical heterogeneity of permeability may be an important reason for the decrease of gas rate.

\section{Ratio of the critical desorption pressure to the initial reservoir pressure}

In general, the greater the depth, the greater the reservoir pressures with the more powerful the reservoir compaction, which result in lower permeability and lower productivity of CBM wells ${ }^{[8]}$. The average pressure coefficient of coal reservoirs $(0.67 \mathrm{MPa} / 100 \mathrm{~m})$ in the study area can be used to calculate the initial reservoir pressure $\left(p_{\mathrm{c}}\right)$. The results show that the $p_{\mathrm{c}}$ in the study area is 2 to $6 \mathrm{MPa}$. Fig. $3 \mathrm{a}$ indicates that the average gas rate per $100 \mathrm{~m}$ has a negative relationship with the $p_{\mathrm{c}}$. When the $p_{\mathrm{c}}$ is more than $4 \mathrm{MPa}$, the wells show a poor gas recovery. For development wells, when successive gas appears, the flowing bottom hole pressure obtained from real-time monitoring system can be regarded as the critical desorption pressure $\left(p_{\mathrm{i}}\right)$. It can be seen that the greater the $p_{\mathrm{i}}$, the higher production of CBM wells (Fig. $3 \mathrm{~b}$ ). When the $p_{\mathrm{i}}$ is in the range of 2 to $2.5 \mathrm{MPa}$, the gas rate of horizontal wells is basically more than $\left.150 \mathrm{~m}^{3} /(\mathrm{d} / 100 \mathrm{~m})\right)$.

Actually, the horizontal well is more complex than the vertical well due to the horizontal well has some branches and veins branch, the ratio of the $p_{\mathrm{c}}$ to $p_{\mathrm{i}}$ is more significance for the development of CBM horizontal wells ${ }^{[9]}$. It can be seen that $p_{\mathrm{c}} / p_{\mathrm{i}}$ has a positive relationship with the gas rate per $100 \mathrm{~m}$. When the $p_{\mathrm{d}} / p_{\mathrm{i}}$ is lower than 0.6 , the horizontal well performed a poor gas recovery; Contrary, the gas rate per $100 \mathrm{~m}$ is basically greater than $150 \mathrm{~m}^{3} /(\mathrm{d} / 100 \mathrm{~m})$ while the $p_{\mathrm{c}} / p_{\mathrm{i}}$ is more than 0.6 (Fig. $\left.3 \mathrm{c}\right)$. 

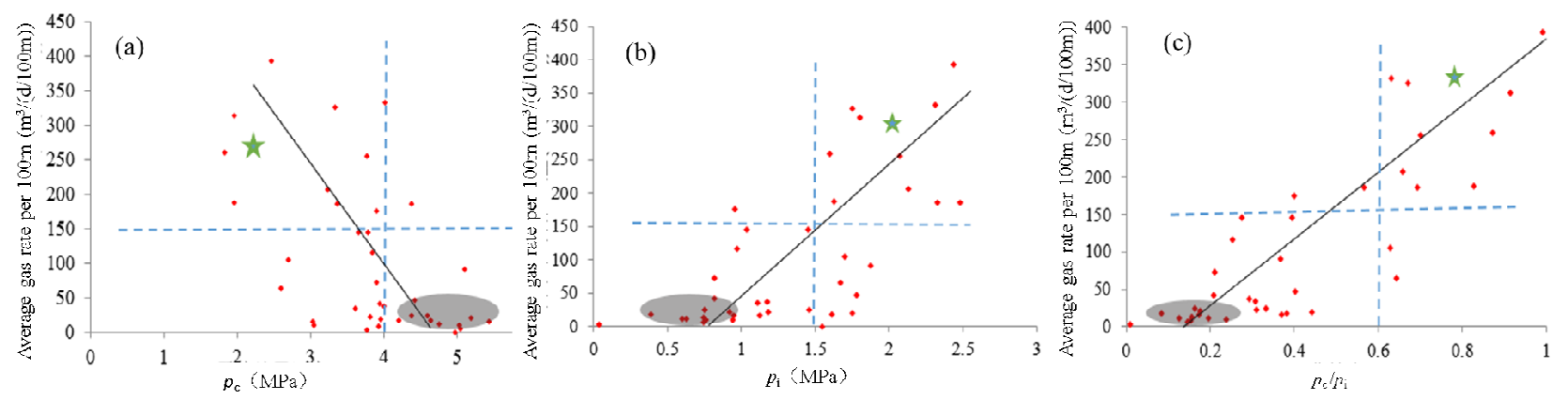

Fig. 3 Scatter map of the average gas rate per $100 \mathrm{~m}$ and initial $p_{\mathrm{c}}(\mathrm{a}), p_{\mathrm{i}}(\mathrm{b})$ and $p_{\mathrm{c}} / p_{\mathrm{i}}(\mathrm{c})$.

\section{Gas content}

Gas content is the material base for the development of CBM wells, while the CBM wells will get high and stable production in the late production process due to adequate gas supply ${ }^{[10]}$. In this work, the gas content was calculated according to Langmuir parameters and the petrophysical properties of the reservoir. The gas content in the study area is generally high (10 to $\left.25 \mathrm{~m}^{3} / \mathrm{t}\right)$. Fig. $4 \mathrm{a}$ indicate that the gas content has a significant influence on the gas production of CBM horizontal well, there are almost no high-yield wells in lower gas content area $\left(<15 \mathrm{~m}^{3} / \mathrm{t}\right)$. When the gas content is more than $20 \mathrm{~m}^{3} / \mathrm{t}$, the proportion of high yield wells increased significantly.
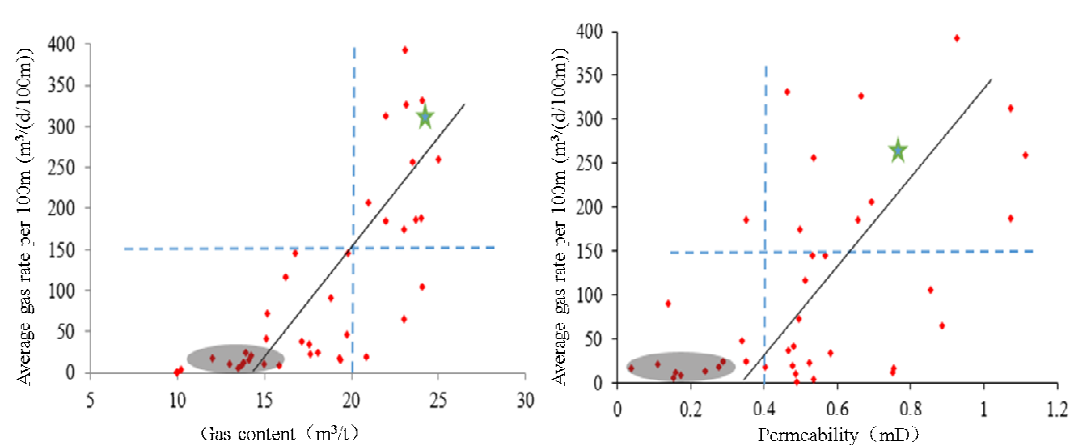

Fig. 4 Scatter map of the average gas rate per $100 \mathrm{~m}$ and the gas content(a),permeability(b).

\section{Permeability}

Although the branch and vein branch of horizontal well can solve the difficult problem of low permeability reservoir, the drainage pressure drop velocity and the expansion of the pressure drop funnel are still affected by the development of fracture. According to the relationship between well testing permeability and depth, the permeability of coal reservoirs in actual CBM wells can be predicted. The results show that the coal reservoirs in Fanzhaung block is a typical extremely-low permeability reservoir with the permeability lower than $1 \mathrm{mD}$. There is a slightly positive relation between the gas rate per $100 \mathrm{~m}$ and permeability, but it is worth noted that the horizontal well is of poor production when the permeability lower than $0.3 \mathrm{mD}$ (Fig. $4 \mathrm{~b}$ ).

\section{Multi-factor}

A coal seam with a larger thickness contributes to more controlled reserve of the CBM wells, which results in stronger gas supply capability and higher gas production. In the Fanzhuang Block, less thickness correlates with greater gas production (Fig. 2b), showing that CBM production is the result of multiple factors, and a single factor (e.g., thickness) does not directly affect CBM production. Thus, two parameters, the gas production potential ( $P=$ the thickness $\times$ the gas content) and the gas production capacity ( $C=P \times$ the permeability), characterize the comprehensive effect of the thickness, the gas content and the permeability. Fig. 5 indicate that $P$ and $\mathrm{C}$ have a good positive correlation with the gas rate per $100 \mathrm{~m}$ of the horizontal wells. When $C$ is more than $60 \mathrm{mD} \times \mathrm{m}^{4} / \mathrm{t}$ or $P$ is more than 120 
$\mathrm{m}^{4} / \mathrm{t}$, the production of horizontal well is basically greater than $150 \mathrm{~m}^{3} /(\mathrm{d} / 100 \mathrm{~m})$, which indicate that high gas production potential and capacity are favorable for gas productivity.
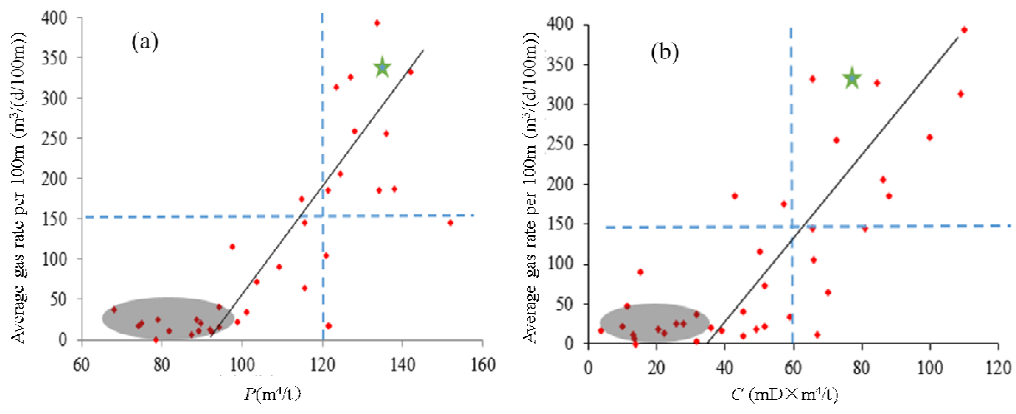

Fig.5 Scatter map of the average gas rate per $100 \mathrm{~m}$ and the gas production potential(a), the gas production capacity(b).

\section{Gray correlation analysis and reservoir classification}

Gray correlation analysis is an important part of the gray system theory, which is also be frequently used to determine whether a close relationship exists between array curves, based on their similarity. The purpose of gray correlation analysis is to quantify the correlation degrees of various factors and present the key factors that affect the system development ${ }^{[11]}$. In this work, the relationship between the factors and the gas rate per $100 \mathrm{~m}$ was determined by the method of gray correlation analysis. The results show that the order of geological factors influencing horizontal well productivity is burial depth, $C, P, p_{\mathrm{d}} / p_{i}$, gas content, and thickness (Table 2). In the process of CBM development, the burial depth determine the permeability, pressure and the development of fracture, while the ratio of the critical desorption pressure to the initial reservoir pressure frequently determines the degree of difficulty of the water drainage and decompression in the CBM reservoir. Besides, it can be seen that $P$ and $C$ can reflect the comprehensive impacts of thickness, gas content, and permeability. The key geological factors affecting CBM horizontal wells productivity in the Fanzhuang Block can be characterized as burial depth, $p_{\mathrm{c}} / p_{i}, P$ and $C$. According to the relationship between these four factors and gas production per $100 \mathrm{~m}$ of actual CBM wells, the coal reservoir is divided into three categories(Table 3) :

Table 2 The results from the grey correction analysis.

\begin{tabular}{ccc}
\hline Factors & Correlation degree & $\begin{array}{c}\text { Ran } \\
\mathrm{k}\end{array}$ \\
\hline Burial depth & 0.7941 & 1 \\
$C$ & 0.6865 & 2 \\
$P$ & 0.6271 & 3 \\
$p_{\mathrm{c}} / p_{\mathrm{i}}$ & 0.5244 & 4 \\
Gas content & 0.5041 & 5 \\
Thickness & 0.5017 & 6 \\
\hline
\end{tabular}

Table 3 classification of the reservoirs of horizontal wells

\begin{tabular}{cccccc}
\hline Type & $\begin{array}{c}\text { Average gas rate per 100m } \\
\left(\mathrm{m}^{3} /(\mathrm{d} / 100 \mathrm{~m})\right)\end{array}$ & $\operatorname{Depth}(\mathrm{m})$ & $p_{\mathrm{c}} / p_{\mathrm{i}}$ & $P\left(\mathrm{~m}^{4} / \mathrm{t}\right)$ & $C\left(\mathrm{mD} \times \mathrm{m}^{4} / \mathrm{t}\right)$ \\
\hline I & $>150$ & $<500$ & $>0.6$ & $>120$ & $>60$ \\
II & $50 \sim 150$ & $500 \sim 700$ & $0.2 \sim 0$. & $100 \sim 120$ & $40 \sim 60$ \\
& & & 6 & & \\
III & $<50$ & $>700$ & $<0.2$ & $<100$ & $<40$ \\
\hline
\end{tabular}

(I): Burial depth $<500 \mathrm{~m}, p_{\mathrm{c}} / p_{\mathrm{i}}>0.6, P>120 \mathrm{~m}^{4} / \mathrm{t}, C>60 \mathrm{mD} \times \mathrm{m}^{4} / \mathrm{t}$. This kind of coal reservoir has good development effect and high economic benefit with the high gas recovery $\left(>150 \mathrm{~m}^{3} /(\mathrm{d} / 100 \mathrm{~m})\right)$. 
(II): Burial depth is 500 to $700 \mathrm{~m}, 0.2<p_{\mathrm{c}} / p_{\mathrm{i}}<0.6,100<P<120 \mathrm{mD} \times \mathrm{m}^{4} / \mathrm{t}, 40<C<60 \mathrm{mD} \times \mathrm{m}^{4} / \mathrm{t}$. The development of this kind of coal reservoir basically has no economic benefit, while the gas production per $100 \mathrm{~m}$ is about $50 \sim 150 \mathrm{~m}^{3} /(\mathrm{d} / 100 \mathrm{~m})$.

(III): Burial depth $>700 \mathrm{~m}, p_{\mathrm{c}} / p_{\mathrm{i}}<0.2, P<100 \mathrm{mD} \times \mathrm{m}^{4} / \mathrm{t}, C<40 \mathrm{mD} \times \mathrm{m}^{4} / \mathrm{t}$. The development effect of this kind of reservoir is poor with no economic benefit, which should be avoided in the process of development as soon as possible.

\section{Conclusions}

a. The coalbed methane (CBM) production performance of 58 horizontal wells in the Fanzhuang block of the Qinshui Basin was tracked, and the main problems in the development of horizontal wells was addressed: Coal reservoir is sensitive to reservoir sensitivity damage; Borehole wall collapse caused by the instability of wellbore in the process of drilling; There are a large number of inefficient wells with no improvement measures.

b. The order of geological factors influencing horizontal well productivity is burial depth, gas production capacity $(\mathrm{C})$, gas production potential $(\mathrm{P})$, ratio of critical desorption pressure to initial reservoir pressure $\left(p_{\mathrm{c}} / p_{\mathrm{i}}\right)$, gas content, and thickness, where the gas production potential and capacity can reflect the comprehensive impacts of thickness, gas content, and permeability.

c. Three types of reservoir model related to the development of CBM horizontal wells was quantitative characterized according to the combination of four parameters (including burial depth, ratio of critical desorption pressure to initial reservoir pressure, the gas production potential and capacity). The high production indexes are the depth of $300 \sim 500 \mathrm{~m}, p_{\mathrm{c}} / p_{\mathrm{i}}>0.6, P>130 \mathrm{~m}^{4} / \mathrm{t}, C>60$ $\mathrm{mD} \times \mathrm{m}^{4} / \mathrm{t}$, and far away from the faults.

\section{Acknowledgments}

This work was financially supported by the Key Project of the National Science and Technology (Grant No. 2011ZX05061), the Project of the University-enterprise Cooperation of PetroChina Huabei Oilfield Company "Development optimization design and matching technology optimization in the coalbed methane (CBM) favorable areas, southern Qinshui Basin" (Grant No. HBYT-YJY-2015-JS-300) and the Project of the PetroChina Huabei Oilfield Company "Research on High-Performance Development Technology in Eastern Mabi Block" (Grant No. 2016-HB-M06). We appreciate the constructive comments and suggestions from the reviewers and the editors.

\section{References}

[1] Y. Lv, D. Tang, H. Xu, and H. Luo: Int. J. Coal Geol. Vol. 96-97(2012), p. 93-108

[2] Z. Chen, Y. Wang, J. Yang, X. Wang, Y. Chen, and Q. Zhao: Acta Petrol. Sin. Vol. 30(2009), p. 409-416

[3] H. Xu, D. Tang, S. Tang, J. Zhao, Y. Meng, and S. Tao: Int. J. Coal Geol. Vol. 121(2014), p. 44-52

[4] Sinayuc. C, Shi, JQ, Imrie. C, Syed. S., Korre. A, and Durucan. S: Energy Procedia, Vol. 22(2011), p.2150-2156.

[5] Y. Li, D. Tang, H. Xu, and T. Yu: J. Petrol. Sci. Eng. Vol. 122(2014), p. 488-496

[6] Y. Yang, D. Tang, Y. Yang, L. Chen, and S. Tao: Coal Sci. Technol. Vol. 43(2015), p. 96-99

[7] Pashin. J. C: Int. J. Coal Geol. Vol. 82(2010), p. 135-146.

[8] Shu. T, Y. Wang, D. Tang, H. Xu, Y. Lv, W. He, Y. Li: Int. J. Coal Geol. Vol. 93(2012), p. 16-22

[9] McKee. C. R., Bumb. A. C: SPE Form Evaluation. Vol. 2(1987), p. 599-608. 
[10] Ross. H. E, Hagin. P, Zoback. M. D: International Journal of Greenhouse Gas Control. Vol.3 (2009), p.774-786.

[11] Deng. J. L: Systems \& Control Letters. Vol.1 (1982).p.288-294 